\title{
Racemization Kinetics of Meluadrine Tartrate in Aqueous Solution
}

\author{
Kazuya Matsuo, ${ }^{*}, a, b$ Youichi Yamamoto, ${ }^{a}$ Noriyuki Kado, ${ }^{a}$ Masahiro Yamazaki, ${ }^{a}$ Osamu Nagata, ${ }^{a}$ \\ Hideo KATO, ${ }^{a}$ and Akira TsuJI ${ }^{b}$ \\ Pharmaceutical Research Laboratory, Hokuriku Seiyaku Co., Ltd., ${ }^{a}$ 1-1 Inokuchi 37, Katsuyama, Fukui 911-8555, Japan \\ and Department of Pharmaceutics, Kanazawa University, ${ }^{b}$ 13-1 Takara-machi, Kanazawa 920-0934, Japan. \\ Received September 11, 2000; accepted October 24, 2000
}

The kinetics of racemization of meluadrine tartrate in aqueous solution was investigated by HPLC, over the pH range of 1.2 to 12 at 40,60 and $80^{\circ} \mathrm{C}$. The racemization was followed by measuring both the residual $(R)-$ enantiomer and formed $(S)$-enantiomer of meluadrine.

The $\mathrm{pH}$-racemization rate profile of meluadrine showed a minimum racemization rate constant between $\mathrm{pH}$ 4 and 6 , and the rate constant increased rapidly with decreasing pH below $\mathrm{pH} 3$. In the basic region, the racemization rate constant showed a maximum at around $\mathrm{pH} 9$.

Four pathways of racemization of meluadrine are proposed, depending on the dissociation state of the phenolic and amino groups. The calculated racemization rate-pH profile agreed well with the observations. The values of activation energy $(95-115 \mathrm{~kJ} / \mathrm{mol})$ suggest that a similar quinoid intermediate is involved throughout the pH range examined.

The objective of this study is to clarify the racemization mechanism of benzylalcohol derivative with phenoric group.

This study offers fundamental knowledge for the other benzylalcohol derivatives, which have similar moiety structure.

Key words racemization; meluadrine; $\mathrm{pH}$-profile; $\beta_{2}$-agonist; phenolic group

Many $\beta_{2}$-adrenoceptor agonists possess a benzylalcohol moiety with chirality at the $\beta$-carbon atom, and the pharmacological activity resides predominantly in the $(R)-(-)$-enantiomer. ${ }^{1)}$ It is well known that the racemization of $\beta_{2}$-adrenoceptor agonists such as catecholamines occurs in aqueous solution, ${ }^{2,3)}$ though many studies were conducted only in the acidic region. ${ }^{4,5)}$

Meluadrine tartrate (Fig. 1) is a novel $\beta_{2}$-adrenoceptor agonist which inhibits spontaneous rhythmic contraction of the uterus. ${ }^{6)}$ The drug is used as the optically pure $(R)$-enantiomer. This paper deals with a kinetic study of meluadrine tartrate racemization over the $\mathrm{pH}$ range from 1.2 to 12 .

\section{Experimental}

Materials Meluadrine $((R)$-enantiomer) L-tartrate and its $(S)$-enantiomer L-tartrate were synthesized at Hokuriku Seiyaku Co., Ltd. All other reagents were of analytical grade.

HPLC Conditions for Enantiomer Assay HPLC (Jasco, Tokyo, Japan) with a ULTRON ES-OVM (4.6 i.d. $\times 150 \mathrm{~mm}, 5 \mu \mathrm{m}$ particle size) column was used to determine the ratio of $(R)$-enantiomer and $(S)$-enantiomer. The mobile phase was a mixture of $\mathrm{pH} 6.8$ phosphate buffer-methanol $(9: 1$, $\mathrm{v} / \mathrm{v})$. The detector wavelength was set at $220 \mathrm{~nm}$, the flow rate of the mobile phase was $0.6 \mathrm{ml} \mathrm{min}^{-1}$ and the column temperature was $30^{\circ} \mathrm{C}$. The retention times of $(R)$-enantiomer and $(S)$-enantiomer were about 8 and $18 \mathrm{~min}$, respectively.

HPLC Conditions for Assay of Total Residual Percent of Meluadrine HPLC (Jasco, Tokyo, Japan) with a TSKgel ODS- $80 \mathrm{~T}_{\mathrm{M}}(4.6$ i.d. $\times 150 \mathrm{~mm}$, $5 \mu \mathrm{m}$ particle size) column was used to determine the total residual percent of $(R)$-enantiomer and $(S)$-enantiomer. The mobile phase was a mixture of pH 2.5 phosphate buffer containing sodium 1-heptanesulfonate-acetonitrile $(3: 1, v / v)$. The detector wavelength was set at $220 \mathrm{~nm}$, the flow rate of mobile phase was $1.0 \mathrm{ml} \mathrm{min}^{-1}$ and the column temperature was $30^{\circ} \mathrm{C}$. The re- tention times of meluadrine and internal standard (clorprenaline) were about 6 and $8 \mathrm{~min}$, respectively.

Calculation of Residual Percent of $(R)$-Enantiomer and Formed Amount of $(S)$-Enantiomer The residual percent of $(R)$-enantiomer and the formed amount of $(S)$-enantiomer were calculated from enantiomer ratio of the above enantiomer assay and total residual percent.

Kinetic Procedure The sample $((R)$-enantiomer or $(S)$-enantiomer) was dissolved in Britton-Robinson buffer or diluted hydrochloric acid adjusted to the appropriate $\mathrm{pH}$ from 1.2 to 12 , to give a concentration of $10 \mathrm{mg} \mathrm{ml}^{-1}$. Aliquots of $10 \mathrm{ml}$ were put in glass ampules, which were then sealed. The ampules were placed in a chamber heated at 40,60 or $80^{\circ} \mathrm{C}$. At intervals, samples were removed from the chamber and assayed.

Determination of Ionization Constants The apparent ionization constants of meluadrine were determined by potentiometry and spectrophotometry. The apparent ionization constants $\mathrm{p} K_{\mathrm{a} 1}$ and $\mathrm{p} K_{\mathrm{a} 2}$, which refer to the dissociation of the phenolic group and the amino group, were 8.35 and 9.99 , respectively (Chart 1).

\section{Results and Discussion}

As shown in Fig. 2, semilogarithmic plots of the residual percent of total meluadrine versus time were reasonably linear and indicated that the degradation of meluadrine followed pseudo-first order kinetics at constant $\mathrm{pH}$ and temperature, at various $\mathrm{pH}$ values.

The disappearance of the $(R)$-enantiomer and the appear-

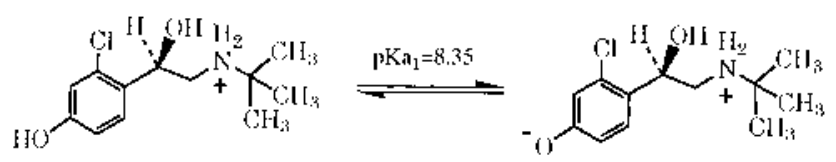<smiles>CC(C)(C)NC[C@@]([Al])(Cl)c1ccc(O)cc1Cl</smiles><smiles>COc1ccc([C@](O)(I)CNC(C)(Cl)C(Cl)(Cl)Cl)c(Cl)c1</smiles>

Chart 1

Fig. 1. Chemical Structure of Meluadrine Tartrate $((R)$-Enantiomer $)$ 


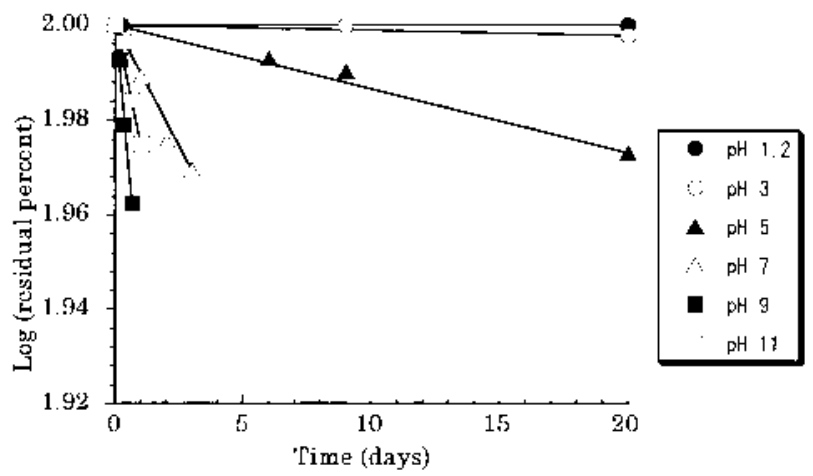

Fig. 2. Apparent First-Order Plots of Residual Percent of Meluadrine Tartrate at Various $\mathrm{pH}$ Values at $80^{\circ} \mathrm{C}$

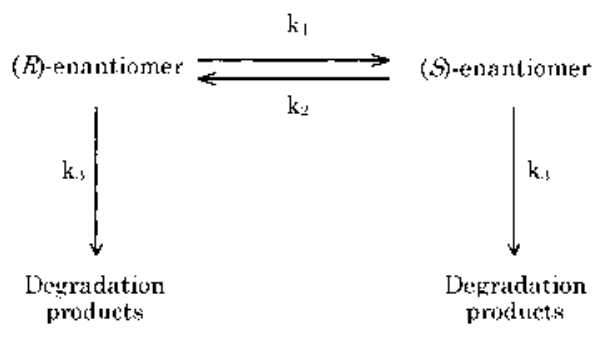

Chart 2

ance of the $(S)$-enantiomer from pure $(R)$-enantiomer and vice versa were measured at various $\mathrm{pH}$ values. Figure 3 shows typical plots of the residual percent of $(R)$-enantiomer and $(S)$-enantiomer against the initial concentration of each enantiomer at $\mathrm{pH} 2,5$ and 9 . Reversible racemization was found to occur. It was found that the reaction rates of the $(R)$ enantiomer and $(S)$-enantiomer were equal.

The concentration-time profiles at various $\mathrm{pH}$ values can be explained in terms of the reactions illustrated in Chart 2, where $k_{1}$ is the racemization rate constant from $(R)$-enantiomer to $(S)$-enantiomer, $k_{2}$ is the reverse rate constant, and $k_{3}$ is the degradation rate constant of meluadrine $((R)$-enantiomer and $(S)$-enantiomer).

According to Chart 2, the following kinetic equations can be written for the $(R)$-enantiomer and $(S)$-enantiomer:

$$
\begin{aligned}
& d[\mathrm{R}] / d t=-k_{1}[\mathrm{R}]+k_{2}[\mathrm{~S}]-k_{3}[\mathrm{R}] \\
& d[\mathrm{~S}] / d t=k_{1}[\mathrm{R}]-k_{2}[\mathrm{~S}]-k_{3}[\mathrm{~S}] \\
& d[\mathrm{R}+\mathrm{S}] / d t=-k_{3}[\mathrm{R}+\mathrm{S}]
\end{aligned}
$$

These equations can be solved as follows ${ }^{7)}$ :

$$
\begin{aligned}
{[\mathrm{R}]=} & \left(\left([\mathrm{R} 0] k_{2}+[\mathrm{S} 0] k_{2}\right) /\left(k_{1}+k_{2}\right)\right) e^{-k_{3} t} \\
& +\left(\left([\mathrm{R} 0] k_{1}-[\mathrm{S} 0] k_{2}\right) /\left(k_{1}+k_{2}\right)\right) e^{-\left(k_{1}+k_{2}+k_{3}\right) t} \\
{[\mathrm{~S}]=} & \left(\left([\mathrm{R} 0] k_{1}+[\mathrm{S} 0] k_{1}\right) /\left(k_{1}+k_{2}\right)\right) e^{-k_{3} t} \\
& -\left(\left([\mathrm{R} 0] k_{1}-[\mathrm{S} 0] k_{2}\right) /\left(k_{1}+k_{2}\right)\right) e^{-\left(k_{1}+k_{2}+k_{3}\right) t}
\end{aligned}
$$$$
[\mathrm{R}]+[\mathrm{S}]=([\mathrm{R} 0]+[\mathrm{S} 0]) e^{-k_{3} t}
$$

where $[\mathrm{R}]$ and $[\mathrm{S}]$ represent the concentrations of $(R)$-enantiomer and $(S)$-enantiomer at time $t$, and [R0] and [S0] represent the initial concentrations of $(R)$-enantiomer and $(S)$ enantiomer, respectively (R0 and S0 are 100 and 0 ). As men-
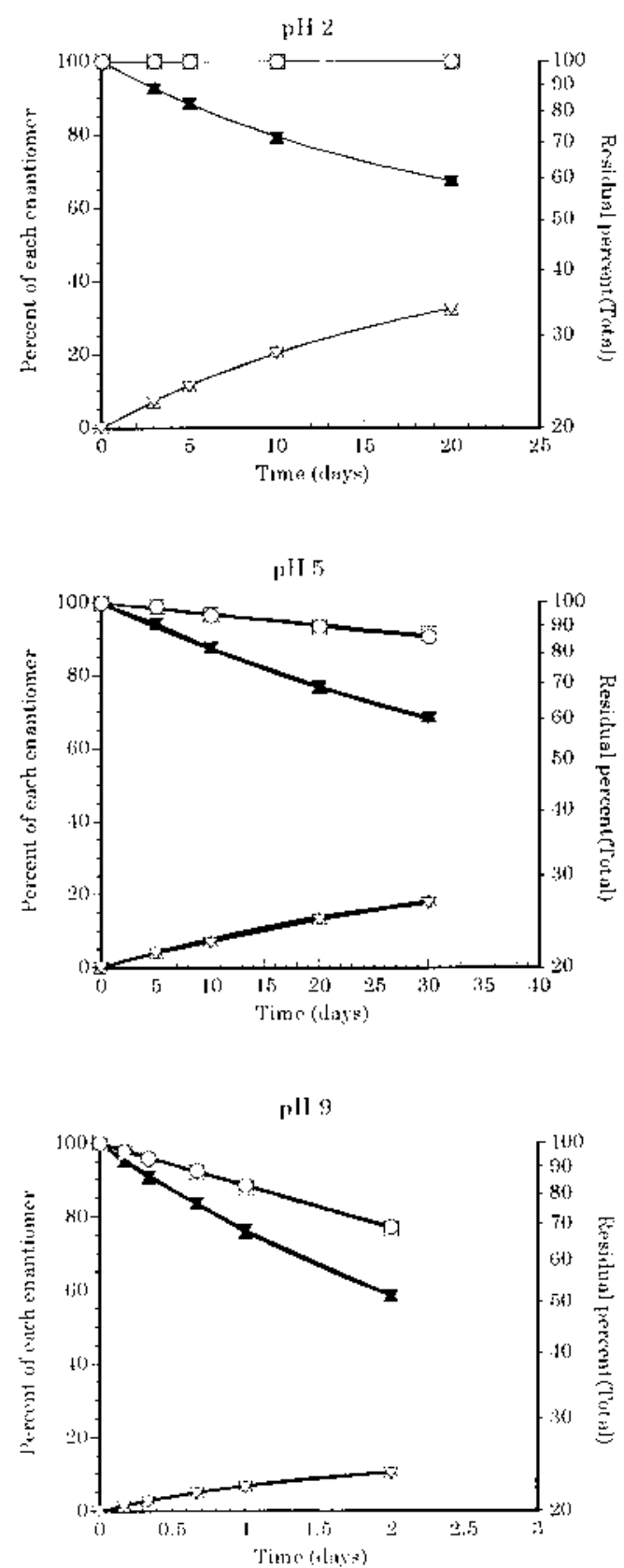

Fig. 3. Time Courses of $(R)$-Enantiomer and $(S)$-Enantiomer at $\mathrm{pH} \mathrm{2,5}$ and 9 , at $80^{\circ} \mathrm{C}$

Total residual percent is plotted semilogarithmically versus time. $\square$ : Total of residual percent of $(R)$-enantiomer and formation of $(S)$-enantiomer from $(R)$-enantiomer. $\bigcirc$ : Total of residual percent of $(S)$-enantiomer and formation of $(R)$-enantiomer from $(S)$ enantiomer. $\nabla$ : Disappearance of $(R)$-enantiomer from $(R)$-enantiomer. $\nabla$ : Appearance of $(S)$-enantiomer from $(R)$-enantiomer. $\mathbf{\Delta}$ : Disappearance of $(S)$-enantiomer from $(S)$ enantiomer. $\triangle$ : Appearance of $(R)$-enantiomer from $(S)$-enantiomer.

tioned above, the reaction rates of the $(R)$-enantiomer and $(S)$-enantiomer are equal, so $k_{1}$ is equal to $k_{2}$ and the equilibrium constant is 1 . Therefore, we obtain:

$$
[\mathrm{R}]=50 \cdot e^{-k_{3} t}+50 \cdot e^{-\left(2 k_{1}+k_{3}\right) t}
$$

$$
[\mathrm{S}]=50 \cdot e^{-k_{3} t}-50 \cdot e^{-\left(2 k_{1}+k_{3}\right) t}
$$

$$
[\mathrm{R}+\mathrm{S}]=100 \cdot e^{-k_{3} t}
$$

If Eq. 7 is substituted into Eq. 8 and rearranged, we obtain Eq. 10 


$$
[\mathrm{R}-\mathrm{S}]=100 \cdot e^{-\left(2 k_{1}+k_{3}\right) t}
$$

The integrated form of Eqs. 9 and 10 is as follows:

$$
\begin{aligned}
& \ln ([\mathrm{R}+\mathrm{S}])=\ln (100)-k_{3} t \\
& \ln ([\mathrm{R}-\mathrm{S}])=\ln (100)-\left(2 k_{1}+k_{3}\right) t
\end{aligned}
$$

The logarithms of $[\mathrm{R}+\mathrm{S}]$ and $[\mathrm{R}-\mathrm{S}]$ were plotted versus time, and $k_{3}$ and $2 k_{1}+k_{3}$ were calculated by the least-squares method. The experimental data as illustrated in Fig. 3 were well fitted by the theoretical values (solid lines) calculated from Eqs. 7, 8 and 9.

The racemization rate- $\mathrm{pH}$ profiles at 40,60 and $80^{\circ} \mathrm{C}$ are shown in Fig. 4. The racemization rate constant reached a minimum between $\mathrm{pH} 4$ and 6 , and increased rapidly with decreasing $\mathrm{pH}$ below $\mathrm{pH} 3$. In the basic region, the racemization rate constant showed a maximum at around $\mathrm{pH} 9$.

Possible racemization mechanisms of meluadrine in aqueous solution are shown in Fig. 5. As shown in (1), racemization in the strongly acidic region should occur by protonation of the hydroxyl group at the $\beta$-carbon atom and dehydration to afford a planar quinoid intermediate, because the rate of racemization decreased by negative unity with decreasing $\mathrm{pH}$ below $\mathrm{pH} 3$ (Fig. 4), which shows the protone-catalyzed racemization.

In the weakly acidic to weakly basic region where the amino group dissociates (2), racemization should occur by elimination of the hydroxyl group at the $\beta$-carbon atom with participation of an ammonium proton, affording a planar quinoid intermediate. As shown in (4), in the strongly basic region, elimination of the hydroxyl group at the $\beta$-carbon atom is caused by electron supply from the dissociated phenolic hydroxyl group. Reaction (3) shows the putative racemization mechanism around $\mathrm{pH}$, where the phenolic hydroxyl group and amino group are both dissociated. The racemization rate around $\mathrm{pH}$, which lies between the two dissociation constants ( 8.35 and 9.99), would be increased by synergy between the electron supply from the dissociated phenolic hydroxyl group and the proton of ammonium ion.

Thus, the reaction may proceed through a planar quinoid form in all $\mathrm{pH}$ regions.

These mechanisms lead to the rate expression in Eq. 13,

$$
\begin{gathered}
k_{\mathrm{pH}}=k_{\mathrm{a}} \cdot\left[\mathrm{H}^{+}\right]+k_{\mathrm{b}} \cdot f_{1}+k_{\mathrm{c}} \cdot f_{2}+k_{\mathrm{d}} \cdot f_{3} \\
f_{1}=\frac{\left[\mathrm{H}^{+}\right]}{\left[\mathrm{H}^{+}\right]+K_{\mathrm{a} 1}} \times \frac{\left[\mathrm{H}^{+}\right]}{\left[\mathrm{H}^{+}\right]+K_{\mathrm{a} 2}} \\
f_{2}=\frac{K_{\mathrm{a} 1}}{\left[\mathrm{H}^{+}\right]+K_{\mathrm{a} 1}} \times \frac{\left[\mathrm{H}^{+}\right]}{\left[\mathrm{H}^{+}\right]+K_{\mathrm{a} 2}} \\
f_{3}=\frac{K_{\mathrm{a} 1}}{\left[\mathrm{H}^{+}\right]+K_{\mathrm{a} 1}} \times \frac{K_{\mathrm{a} 2}}{\left[\mathrm{H}^{+}\right]+K_{\mathrm{a} 2}}
\end{gathered}
$$

$K_{\mathrm{a} 1}$ : Dissociation constant for $p$-hydroxyl group $\left(\mathrm{p} K_{\mathrm{a} 1}=8.35\right)$

$K_{\mathrm{a} 2}$ : Dissociation constant for maino group $\left(\mathrm{p} K_{\mathrm{a} 2}=9.99\right)$

where $k_{\mathrm{a}}$ represents the rate constant for the specific hydrogen ion-catalyzed process, and $k_{\mathrm{b}}, k_{\mathrm{c}}$ and $k_{\mathrm{d}}$ represent the rate constants depending on cationic, zwitterionic and anionic processes, respectively.

In Fig. 4, the solid lines represent the theoretical curves according to Eq. 13, calculated by NONLIN. ${ }^{8)}$ The rate constants that produce the best fit to the observed rate- $\mathrm{pH}$ pro-
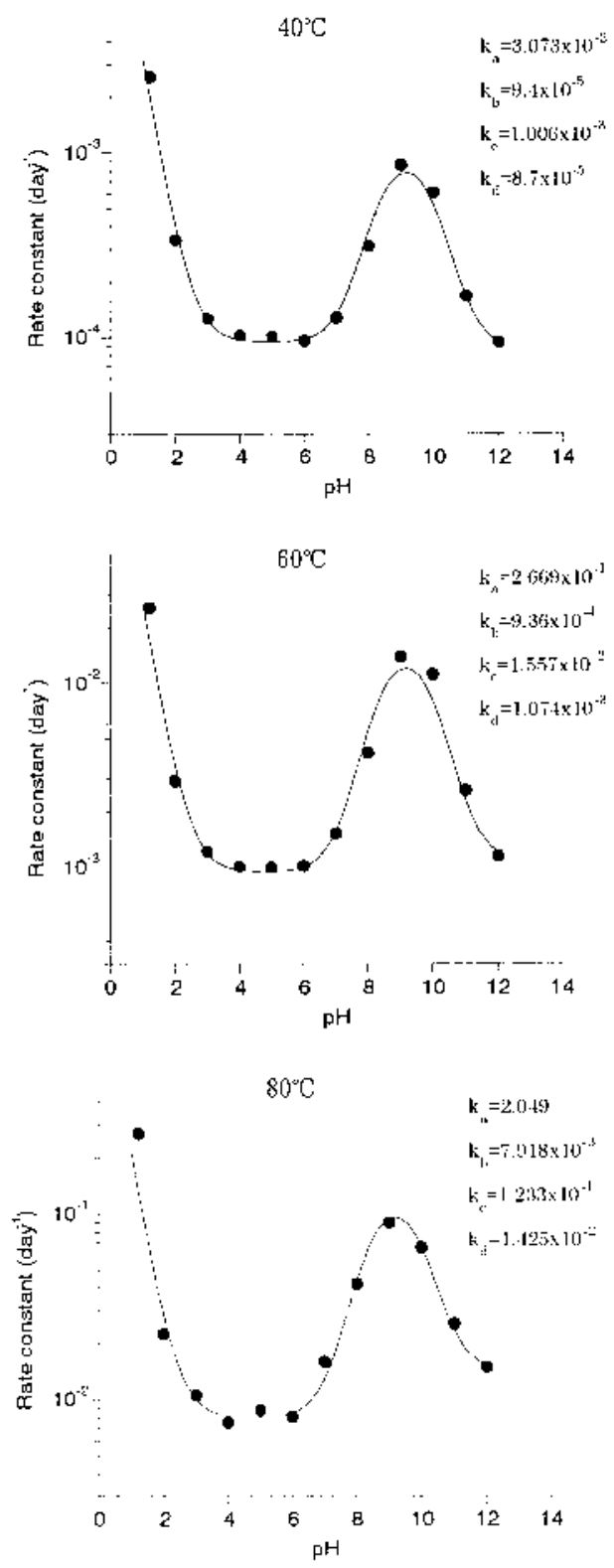

Fig. 4. Rate Constant-pH Profiles for Racemization of Meluadrine Tartrate in Aqueous Solution

Solid line: Curve calculated with "NONLIN" according to Eq. 13. Points: Experimental values. $k_{\mathrm{a}}, k_{\mathrm{b}}, k_{\mathrm{c}}$ and $k_{\mathrm{d}}$ : rate constants defined in Eq. 13 .

file at each temperature are shown in the figure. The good agreement of calculated and observed values indicates that this equation adequately describes the kinetics of racemization of meluadrine.

Figure 6 shows Arrhenius plots of the racemization rate constants at various $\mathrm{pH}$ values. The activation energies were between 95 and $115 \mathrm{~kJ} / \mathrm{mol}$ and were similar at all $\mathrm{pH}$ values. This is consistent with the idea that a similar intermediate, is involved in all the racemization processes.

\section{Conclusion}

The kinetics of racemization of meluadrine tartrate in aqueous solution was investigated by HPLC. The racemization rate constant showed a minimum between $\mathrm{pH} 4$ and 6 , and increased rapidly with decreasing $\mathrm{pH}$ below $\mathrm{pH} 3$. In the basic region, the rate showed a maximum at around $\mathrm{pH} 9$, 

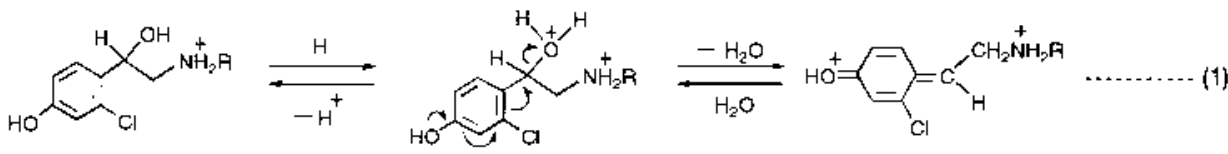<smiles>C=CC[NH2+][CH]C(O)c1ccc(O)cc1Cl</smiles><smiles>CC1(c2ccc(O)cc2Cl)CN2CCC1C2</smiles><smiles>C#C</smiles><smiles>NCCC1C=CC([OH+])=CC1Cl</smiles><smiles>C1C[Te]C1</smiles><smiles>[R]NC[C@H](O)c1ccc(OC)cc1Cl</smiles><smiles>C=C</smiles><smiles>COc1ccc(C2(C)CN3CNCC2(C)O3)c(Cl)c1</smiles><smiles>[CH]=CC=O</smiles><smiles>[R]NCC=C1CCC(=O)C=C1Cl</smiles><smiles>C=C=C</smiles><smiles>NCC(O)(O)C1C=CC2(O)C=C(Cl)C1C2</smiles><smiles>CCO</smiles><smiles>O=CCC=C1C=CC(=O)C=C1Cl</smiles><smiles>[13CH3]</smiles>

Fig. 5. Proposed Racemization Mechanisms of Meluadrine Tartrate in Aqueous Solution

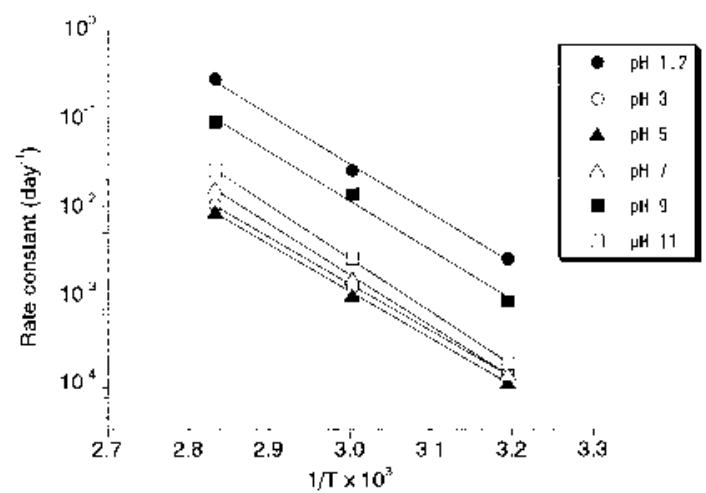

Fig. 6. Arrhenius Plots of Racemization Rate Constants at Various $\mathrm{pH}$ Values

which is intermediate between the two dissociation constants (8.35 and 9.99). The racemization is proposed to proceed via proton-catalyzed and spontaneous pathways, depending on the dissociation state of meluadrine, and the racemization rate is influenced by the dissociation states of the phenolic and amino groups. The activation energies at various $\mathrm{pH}$ values were between 95 and $115 \mathrm{~kJ} / \mathrm{mol}$, suggesting that a similar planar quinoid intermediate is involved in the racemization processes in all $\mathrm{pH}$ regions.

\section{References and Notes}

1) Patil P. N., Miller D. D., Trendelenburg U., Pharmacol. Rev., 26, $323-$ 392 (1974).

2) Hellberg H., J. Pharm. Pharmacol., 7, 191-197 (1955).

3) Schroeter L. C., Higuchi T., J. Am. Pharm. Assoc., 47, 426-430 (1958).

4) Venter D. P., Tetrahedron, 47, 5019-5024 (1991).

5) Merritt M. V., Anderson D. B., Basu K. A., Chang I. W., Chean H. J., Mukundan N. E., Flannery C. A., Kim A. Y., Valshampayan A., Yens D. A., J. Am. Chem. Soc., 116, 5551-5559 (1994).

6) Ohashi T., Hashimoto S., Morikawa K., Kato H., Ito Y., Asano M., Azuma H., Eur. J. Pharmacol., 307, 315-322 (1996).

7) Hashimoto N., Tasaki T., Tanaka H., J. Pharm. Sci., 73, 369-373 (1984).

8) Statistical Consultants Inc.: PCNONLIN and NONLIN84: Software for the Statistical Analysis of Nonlinear Models, Am. Stat., 40, 52 (1986). 